\title{
O PASSO INAUGURAL DA LINGUÍSTICA TEÓRICA NO BRASIL
} Ricardo Cavaliere*

Resumo: Este texto visa traçar um breve comentário sobre a obra Traços gerais de linguística, escrita por Júlio Ribeiro em 1880 e publicada como um dos volumes dedicados à vulgarização da ciência que compuseram a Biblioteca Útil, da Livraria Popular de Abilio A. S. Marques. O opúsculo, do ponto de vista historiográfico, é o primeiro texto sobre linguística geral publicado no Brasil, em cujas páginas desfilam os principais conceitos com que a então revolucionária linguística evolucionista buscava explicar a origem e a evolução da língua, bem como o mecanismo de processamento da linguagem humana no cérebro.

Palavras-chave: Historiografia linguística. Texto precursor. Linguística brasileira.

\section{INTRODUÇÃO}

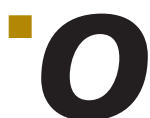

Brasil, à semelhança dos demais países sul-americanos, sempre se caracterizou por desenvolver estudos linguísticos à luz de paradigmas importados dos grandes centros científicos mundiais, um fato epistemológico que se pode denominar "linguística de recepção". Ao longo da primeira metade do século XIX, as teses da grammaire raisonnée chegaram às páginas dos primeiros compêndios gramaticais brasileiros sobretudo pela obra de César Dumarsais (1676-1756), Antoine de Tracy (1754-1836), Étienne de Condillac (1714-1780), Nicolas Beauzée (1717-1789) e, mais diretamente, Jerônimo Soares Barbosa (1737-1816). Cuidava-se, então, ao longo de mais de meio século, desde a primeira edição, em 1806, do Epitome da gramática portuguesa, por Antônio de Morais Silva (1755-1824), até a publicação, em 1880, da Gramática elementar portuguesa, por Antônio Estêvão da Costa e Cunha (1839-?), de uma aplicação das teses racionalistas à descrição do português em textos gramaticais prioritariamente destinados ao ensino da língua vernácula. 
Com a chegada do paradigma histórico-comparativo às páginas gramaticais brasileiras, cujo pioneirismo se atribui à Gramática portuguesa (1911 [1881]) por Júlio Ribeiro (1845-1890), o propósito eminentemente pedagógico das gramáticas cede espaço para publicações de caráter bivalente, a um tempo prescritivas e descritivas, visto que a nova visão com que se buscava enxergar o fenômeno da linguagem humana impunha uma postura dita "científica", em que o escopo de ensinar a norma linguística- padrão irmanava-se ao de descrever as regras de funcionamento da lingua. Raras eram as obras especificamente destinadas ao tratamento meramente teórico da língua, textos que se podem caracterizar como doutrinários, ou exclusivamente científicos, visto que tinham o propósito de difundir as novéis teses da linguística oitocentista no ambiente acadêmico brasileiro. Dentre esses textos doutrinários, destaca-se o opúsculo Traços gerais de linguistica, publicado por Júlio Ribeiro em 1880, cujo teor é ainda pouco conhecido e, portanto, merecedor de maior atenção no âmbito dos estudos historiográficos.

Nas linhas que se seguem, procedemos a uma análise descritiva dessa obra pioneira, que, no estado atual da pesquisa linguístico-historiográfica, deve ser considerada o texto introdutor da linguística como ciência no Brasil ${ }^{1}$, a par de constituir-se o primeiro estudo brasileiro sobre a linguagem humana desvinculado da descrição do vernáculo com fins pedagógicos.

\section{SOBRE O AUTOR}

Júlio César Ribeiro Vaughan foi, sem dúvida, uma das personalidades mais controversas e inquietantes do cenário político-cultural brasileiro na segunda metade do século XIX. Nascido na cidade de Sabará, em 1845, Júlio Ribeiro notabilizou-se por uma intensa atividade intelectual, que lhe deu projeção expressiva no campo da Linguística, da Filologia, da Literatura, do Jornalismo, da atividade política, bem como no âmbito da pregação religiosa. Sua morte em 1890, na cidade de Santos, abreviou uma carreira que se revelava tão intensa quanto diversificada e pôs termo, igualmente, a uma existência conturbada pela crítica severa que lhe faziam os pares, bem como pela própria personalidade intransigente e infensa ao trato social.

Filho de George Washington Vaughan e da professora Maria Francisca da Anunciação Ribeiro, o jovem Júlio cresceu em uma família castigada pelas dificuldades financeiras, a que acrescia, segundo nos informa Cobra (2011), a dor moral provocada pelas constantes ausências do pai. O espírito de superação e o obstinado esforço pela formação intelectual do filho foram os traços da personalidade de Maria Francisca que conferiram ao filho um futuro promissor. Após os anos de preparação primária com a própria mãe, o jovem Júlio é matriculado no Colégio Baependiano, um internato católico localizado na cidade de Baependi, Minas Gerais, onde, já a partir do penúltimo ano de estudos, iniciou-se no magistério como professor colaborador de latim (COBRA, 2011, p. 30). Mais tarde, continuou sua preparação básica no Colégio Marinho do Rio de Janeiro e, logo

1 Não são poucos os que, equivocadamente, atribuem a Joaquim Mattoso Câmara Jr. o privilégio de haver introduzido a linguística no Brasil em face da publicação de Princípios de linguística geral (1941) veja, por exemplo, Ilari (2009), Matos (2004) e Vandresen (2006). Rodrigues (2005, p. 12) chega a afirmar que Mattoso Câmara "foi não apenas o pioneiro, mas o propugnador constante e imbatível dos estudos Lingüísticos sérios, cientificamente bem fundados". Mais adequadamente, Uchôa (2004) e Leite (2004) asseveram que Mattoso Câmara é o introdutor do paradigma estruturalista da Linguística no Brasil. 
depois, no Colégio Militar, onde, segundo seus biógrafos, teve um desempenho apagado (cf. COBRA, 2011, p. 43; IRMÃO, 1978, p. 39). Após os anos na escola militar, e impedido de cursar o ensino superior em face de sua precária situação financeira, Ribeiro vê-se obrigado a ganhar a vida no magistério, fato que o levou a tentar o concurso para professor de primeiras letras em São Paulo. Afinal, seria esse o caminho que mais tarde conferiria ao jovem e talentoso docente o reconhecimento de seus pares como filólogo de grande erudição e linguista renovador das teses sobre o estudo da língua no Brasil.

Ribeiro atuou em vários estabelecimentos de ensino, entre os quais destaca-se a Escola Americana, inaugurada em 1870 pelo missionário George Whitehill Chamberlain (1839-1902). Completava a renda mensal com aulas particulares de latim, francês, inglês, geografia, primeiras letras e matemática (cf. IRMÃO, 1978 , p. 92). Sua atividade nesse campo pedagógico desenvolvia-se em várias cidades do interior paulista, tais como Lorena, Guaratinguetá, Pindamonhangaba e Taubaté - lugares em que ganhava a vida dando aulas particulares a filhos de famílias abastadas -, além de Campinas, Lorena, Piracicaba, Capivari e, sobretudo, Sorocaba, onde viveu por muitos anos.

No plano religioso, segundo nos informa Cobra (2011, p. 48), Ribeiro percorreu três fases distintas: uma fase católica, que vai do nascimento a 1870; uma fase protestante, dedicada à doutrina presbiteriana, que vai de 1870 a 1885; e uma fase mergulhada no ateísmo, que perdurou de 1885 até sua morte em 1890. Diga-se, por necessário, que iniciado na fé católica, por influência da mãe, Ribeiro cogitou de seguir a carreira eclesiástica, havendo-se inclusive matriculado no Seminário de Mariana. Não são bem claras as forças espirituais, ou possivelmente as sendas do destino, que levaram Ribeiro a tão radicais mudanças em sua vida religiosa. Fato é que o jovem que pretendera tornar-se padre católico viria, afinal, a professar a fé protestante como pastor. E é, efetivamente, nessa fase protestante que sua produção intelectual mais e melhor se expressa, seja no campo da Linguística, seja no jornalismo ou na literatura.

Liberal e republicano, atributos que bem se coadunavam com o ideário presbiteriano, Ribeiro conseguiu espaço para expressar sua personalidade forte em manifestos e artigos publicados em jornais, imerso em um cenário político conturbado que já indicava a derrocada do Segundo Império. Conforme nos informa Silveira (2008), em suas Cartas sertanejas, Ribeiro (1908, p. 13-14) demonstra ciência de seu espírito combativo em afirmações como "Se me aprouver, irei até o paradoxo, chegarei até ao absurdo".

Já definitivamente instalado em Sorocaba, onde fundou o jornal O Sorocabano, Ribeiro envolve-se com o movimento maçônico e abre uma luta franca em favor da República. Segundo Silva (2012, p. 40), "na trajetória intelectual de Júlio Ribeiro percebe-se uma aproximação entre presbiterianos e maçons contra um arqui-inimigo comum: o catolicismo".

É por essa época, em que se encontra em rara estabilidade financeira e espiritual, que Júlio Ribeiro se casa com Sofia Aureliana de Sousa Ribeiro, de cujo enlace nasceram três filhos: Selomith, Joel e Jorge, a primeira precocemente falecida aos quatro anos. O casamento, lamentavelmente, foi um fracasso, em parte devido ao espírito introvertido e turbulento de Ribeiro, em parte devido à fragilidade de Sofia, que, prostrada por uma vida solitária e infeliz, entregou-se à embriaguez (cf. COBRA, 2011, p. 80). Em 1979, morre Sofia, levada pela depressão profunda, deixando sob a responsabilidade do marido a criação do filho Joel e, sob a guarda da avó paterna, o filho Jorge. 
Homem de espírito vanguardista, Ribeiro ocupou as atenções no cenário literário dos Oitocentos como linguista ledor dos grandes nomes da escola histórico-comparativista e introdutor do evolucionismo linguístico no Brasil. A preferência pela nova ordem paradigmática pode resumir-se em um breve parágrafo de sua Gramática portuguesa (RIBEIRO, 1911 [1881], p. I), em que sintetiza: "Abandonei por abstractas e vagas as definições que eu tomára de Burgraff [sic]: preferi amoldar-me ás de Whitney, mais concretas e claras". Por sinal, é de William Whitney (1827-1894) a definição de gramática que abre a Introdução de sua gramática: "Grammatica é a exposição methodica dos factos da linguagem" (RIBEIRO, 1911 [1881], p. 1).

Autor que bem expressa o momento de transição por que passa a descrição linguística no Brasil, Ribeiro alterna-se entre a citação de nomes expressivos do modelo histórico-comparativo e da Filologia Românica - citem-se Friedrich Diez (1794-1876), Max Müller (1823-1900), Adolfo Coelho (1847-1919) entre outros - e de representantes da antiga ordem racionalista, tais como Pierre Bruggraff (1803-1881) e Antônio José dos Reis Lobato (1721-1804). Suas fontes imediatas, entretanto, que o inspiraram na ordenação da matéria gramatical e nos conceitos sintáticos, foram, respectivamente, o escocês Alexander Bain (1818-1903) e o inglês Charles Peter Mason (1820-1900).

No campo da literatura, Júlio Ribeiro deixou poucas obras, das quais a que mais repercussão obteve foi o romance naturalista A Carne (1888), em que explora o tema da falência moral da sociedade novecentista e o perfil da mulher em uma ordem social impregnada de interesse, traição e perversão. O livro contribuiu para conferir a Ribeiro o caráter de "autor maldito", fato que repercutiu em sua vida religiosa e, também, em sua vida intelectual, já que passou a ser vítima de insinuações infundadas acerca de sua probidade como gramático. Não são poucas as acusações de plágio que lhe foram imputadas, sobretudo com respeito à sua Gramática portuguesa (RIBEIRO, 1911 [1881]), todas absolutamente infundadas.

\section{BREVE ANÁLISE BIBLIOLÓGICA DA OBRA ${ }^{2}$}

\section{Seccionamento físico}

A obra Traços gerais de linguística constitui o volume III da coleção denominada Biblioteca Útil. O livro tem 120 páginas, numeradas no ângulo superior direito desde a página 16, que corresponde à segunda página do capítulo 1, até a página 117 , em que se finaliza o capítulo 9 . O volume, produzido em formato in-16. ${ }^{\circ}$, segue o padrão de encadernação simples ${ }^{3}$, em papel cartonado na cor grená, a que se sobrepôs uma folha estilizada em padrão marmorizado de cor bege e grená. O efeito geral resulta em capa e contracapa marmorizadas ao lado de uma tarja grená vertical que se estende do terço esquerdo da capa ao terço direito da contracapa, passando pela lombada. A capa e a contracapa não têm quaisquer dizeres seja na face externa ou na interna, fato que reforça a despersonalização do volume como parte de uma coleção. A lombada traz o nome do 
autor J. Ribeiro separado do título Traços Geraes de Linguistica em caixa alta, além do ano de publicação: 1880 .

O corpo da obra é impresso em papel de imprensa (newsprint), gramatura provável de $48,8 \mathrm{~g} / \mathrm{m} 2$, que comumente se utilizava nas tipografias brasileiras do século XIX para jornais e publicações de baixo custo orçamentário. A rigor, trata-se do mesmo papel utilizado pelo jornal paulista A Gazeta do Povo, em cuja tipografia foi impressa a obra. Há uma guarda e uma contraguarda em papel de $120 \mathrm{~g} / \mathrm{m} 2$ aproximadas, que se estendem em escarcela. No volume que analisa$\operatorname{mos}^{4}$, a folha de rosto traz estampado o carimbo da Sociedade de Estudos Filológicos de São Paulo.

\section{Seccionamento orgânico}

A estrutura orgânica da obra apresenta os seguintes segmentos: 1. parte pré-textual: apresentação da Biblioteca Útil, obras da Biblioteca Útil, falso rosto, página de identificação da Tipografia, folha de rosto, página de direitos autorais, prefácio assinado pelo autor; 2. parte textual, composta pela introdução e nove capítulos, que serão objeto de análise adiante; 3 . parte pós-textual, com sumário (intitulado "indice"), errata, obras à venda na Livraria Popular.

Seguindo o padrão estético da época, a folha de rosto é composta de tipos variados, embora em harmonia estética, com uso de traços horizontais e uma vinheta. Estrutura-se da seguinte forma: BIBLIOTHECA UTIL/ III/TRAÇOS GERAES/ de/ LINGUISTICA/ por/ Julio Ribeiro/ Livraria Popular/de/ Abilio A. S. Marques - Editor / S. Paulo - 1880. No tocante aos direitos autorais, registra-se a copropriedade, em Portugal, da Livraria Internacional de Ernesto Chardron, fundada em 1869 no Porto, uma das mais prestigiadas casas editoriais portuguesas do século XIX, que viria a denominar-se Livraria Lello e Irmão Ltda., depois simplesmente Livraria Lello, cuja sede, na cidade do Porto, é considerada uma das joias da arquitetura neogótica portuguesa.

\section{EM PROL DA VULGARIZAÇÃo dA CIÊNCIA: A BIBLIOTECA ÚTIL}

A Biblioteca Útil foi fundada por Abílio Aurélio da Silva Marques ${ }^{5}$ em 1880. Sua concepção bibliográfica erigiu-se sobre os pilares do positivismo reinante no panorama intelectual brasileiro do final do século XIX, razão por que não terá sido fortuito que o primeiro volume publicado tenha sido exatamente a tese Do espirito positivo, de Augusto Comte (1798-1857), traduzida por Joaquim Ribeiro de Mendonça (?-?), presidente da Sociedade Positivista do Rio de Janeiro. Por sinal, a apresentação da Biblioteca Útil, que abre o volume que ora estudamos, estampa em destaque o nome de Abílio Marques, como editor, e a cidade de São Paulo como local da edição. O destaque a São Paulo está em sintonia com a concentração de nomes importantes do positivismo brasileiro na terra dos ban-

4 Agradecemos ao colega Manuel Gonçalo Fernandes, proprietário do volume, pela gentileza de seu empréstimo para o presente estudo.

5 Pouco se sabe sobre Abílio A. S. Marques. Trata-se de jornalista e editor português radicado em São Paulo. Foi casado com Maria Núncia Gomes Marques, com quem teve ao menos um filho (Family Search). Dedicou-se à causa do Positivismo, havendo sido responsável pela publicação de vários textos de difusão doutrinária. Foi colaborador do jornal Província de São Paulo, hoje O Estado de S. Paulo, havendo muitos de seus textos sido reunidos no volume Interesses Da Colonia Portugueza na Provincia de S. Paulo, Brazil: Artigos Publicados na Provincia de São Paulo, disponível hoje em edições recentes digitalizadas (MARQUES, 2013). 
deirantes, a maioria vinculada à Faculdade de São Paulo, tais como Antônio da Silva Jardim (1860-1891), cuja breve existência pontuou pelas causas republicana e abolicionista, Rangel Pestana (1839-1903), Pedro Lessa (1859-1921), Joaquim Francisco de Assis Brasil (1857-1938), Manuel Ferraz de Campos Sales (1831-1913), Martinho Prado Júnior (1843-1903), entre outros ${ }^{6}$.

Outro vínculo significativo da Biblioteca Útil com as ideias positivistas percebe-se na composição de seus colaboradores, entre os quais citem-se Américo Brasiliense (1833-1896), Antonio Caetano de Campos (1844-1891), José Leão (1850-1904) e Silvio Romero (1851-1914), todos nomes influentes do positivismo no Brasil. A perspectiva editorial projetava uma difusão maior das conquistas científicas que deslumbravam o homem no fin de siécle, cujo escopo procurava coadunar a informação tecnológica a uma linguagem simples, desprovida de terminologia excessivamente técnica. Como adverte o prefácio de Traços, cuja autoria presumidamente se deve ao próprio Abílio Marques, a coleção visava a "popularizar, por meio de edições baratas, as artes e as sciencias que formam o patrimônio do saber, emfim todas as idéas modernas e direcções novas que appareceram no mundo civilizado" (RIBEIRO, 1880, p. 3).

Sem dúvida, a vulgarização da ciência nos tempos mais recentes toma impulso na segunda metade do século XIX. Da França chega-nos o exemplo da Bibliothèque scientifique internationale, inicialmente dirigida por Émile Alglave (1842-1928) e publicada pela Librairie Félix Alcan, a qual alcançou 120 volumes entre 1874 e 1914. Considerada "original e audaciosa" (cf. BÉGUET, 1990, p. 58) dado seu projeto editorial simultâneo em francês, inglês, alemão, russo e italiano, a Bibliothèque scientifique decerto terá servido de inspiração para a fundação da Biblioteca Útil de Abílio Marques, dada a evidente identidade dos dois projetos editoriais.

O projeto de Abílio Marques, assim, buscava trazer para o Brasil os esforços franceses pela "vulgarização da ciência" , termo preferivel a "popularização da ciência" (cf. RAICHVARG; JACQUES, 1991), aparentemente uma atitude consonante com a tradição que o termo adquiriu no decurso da história do saber, desde a concepção da Vulgata como texto popularizador da Bíblia em latim, passando pelos esforços que se podem identificar já na época medieval com as várias traduções do De proprietatibus rerum de Bartolomeu Ânglico (1203-1272) para várias línguas vernáculas ${ }^{8}$. O expressivo impulso que a vulgarização científica ganha a partir da segunda metade do século XIX decerto se deve à emersão de uma episteme cientificista no corpo da sociedade, a ponto de tornar os temas sobre tecnologia e ciência aplicada matéria reincidente nos jornais e almanaques, bem como assunto de conversação efusiva nos salões da sociedade letrada. Esse clima futurista, que especulava acerca dos avanços e conquistas da humanidade sobre os trilhos da alta tecnologia, deu margem ao aparecimento de vários textos dedicados à vulgarização da ciência, obviamente uma oportuna iniciativa que propiciou lucro significativo às casas editoriais.

6 Não obstante a relevância inequívoca do núcleo positivista em São Paulo, saliente-se que as ideias comtianas grassaram por várias províncias do Império, a começar pela figura exponencial de Júlio de Castilhos (1860-1903) no Rio Grande do Sul. Sobre a presença das ideias positivistas em solo brasileiro no século XIX, leia necessariamente Costa (1956), Torres (1957), Lins (1967) e Soares (1998).

7 Na mesma linha, antes da Biblioteca Útil, surge no século XIX o periódico O vulgarizador: o jornal dos conhecimentos, publicado entre os anos de 1877 e 1880 por Augusto Emílio Zaluar (1825-1882). Leia, a respeito, Oliveira e Matta (2011).

8 A obra enciclopédica de Bartolomeu Ânglico foi traduzida, desde o fim do século XII até o século XV, para o francês, o italiano, o alemão, o holandês, o espanhol e o occitano. Leia, para mais informações, Ducos (2014). 


\section{O ENGARRAFAdOR DE NOVAS IDEIAS INTRODUZ A LINGUística NO BRASIL}

Terá sido por modéstia, ou talvez por rigor acadêmico, que Júlio Ribeiro, em uma nota ao leitor, compara-se aos engarrafadores de vinhos preciosos, que fazem ostentar o nome no rótulo ao lado da chancela dos produtores. A observação jocosa ressalva o fato de que as ideias linguísticas que se expõem nas páginas dos Traços são da lavra de nomes preeminentes da Linguística oitocentista, "cujos ensinamentos repeti, cujas palavras por vezes trasladei litteralmente” (RIBEIRO, 1880, p. 9). Saliente-se que a preocupação com a citação expressa das fontes doutrinárias, com detalhada referência aos autores de quem recolheu uma teoria específica, constitui um traço recorrente na obra de Ribeiro. No prefácio de sua Gramática portuguesa (1881), por exemplo, informa ao leitor que sua definição de gramática é absorvida de William Whitney (1827-1894), ao passo que as teses da descrição sintática utilizada são inspiradas no "systema germanico de Becker" (1775-1849), mediante leitura da English grammar, por Charles P. Mason (1879 [1858]).

Não nos surpreende, pois, que Ribeiro apresente ao leitor Traços gerais de linguistica, já em suas primeiras linhas, as principais fontes em que se abeberou para construir o panorama teórico e metodológico da linguística de seu tempo, entre eles Franz Bopp (1791-1867), August Schleicher (1821-1868), Jacob Grimm (1785-1863), Max Müller (1823-1900), Friedrich Diez (1794-1876) e Michel Bréal (1832-1915). Ressalte-se a citação de dois portugueses, Teófilo Braga (1843-1924) e Adolfo Coelho (1847-1919), e um brasileiro, Manuel Pacheco da Silva Jr. (1842-1899), decerto uma deferência a três dos linguistas que mais se destacavam à época na aplicação do método histórico-comparado na descrição do português.

De resto, nessa página inaugural, Ribeiro não perde a oportunidade de uma referência depreciativa ao modelo racionalista que ainda habitava as páginas da Gramática portuguesa (1871[1866]), de Sotero dos Reis (1800-1871), cuja primeira edição precedera aos Traços em uma década e meia. Ao dizer que "entre nós ainda há muita gente de bom saber a acreditar piamente que em materias de filologia e de linguistica disse Sotero dos Reis a ultima palavra" (RIBEIRO, 1880, p. 9), Ribeiro comprova a tese da "tensão essencial" (essential tension) a que se refere Thomas Kuhn (1922-1996) ao tratar da ruptura de paradigmas científicos $^{9}$. Caberia, decerto, a um jovem linguista, formado nas bases da gramática racionalista, o papel inovador que desviaria os rumos dos estudos linguísticos brasileiros na penúltima década do século.

\section{UM TOgUE DE ORDEM POSITIVISTA NA INVESTIGAÇÃO LINGUísTICA}

Não é fortuita a presença de Auguste Comte (1798-1857) como o primeiro nome entre os intelectuais citados por Júlio Ribeiro na apresentação (intitulada Ao Leitor) de seu opúsculo sobre a ciência linguística ${ }^{10}$. Com efeito, a efetiva re-

9 Nas palavras de Kuhn (1977, p. 227, tradução nossa), "somente os pesquisadores firmemente enraizados na tradição científica de seu tempo são propensos a desconstituí-la e fazer emergir uma nova tradição".

10 Além de Comte e dos linguistas já aqui referidos, Ribeiro cita nominalmente Herbert Spencer (1820-1903), Charles Darwin (18091882), Edward Tylor (1832-1917), Ernst Haeckel (1834-1919), Paul Broca (1824-1880), Paul Topinard (1830-1911), Jules Bernard Luys (1828-1897), Auguste Brachet (1845-1898). Um estudo mais acurado da presença desses pensadores no texto de Ribeiro certamente ajudará a abrir as cortinas de seu horizonte de retrospecção. 
volução que então se instala na investigação do fenômeno linguístico reside em uma perspectiva metodológica em que a angustiante busca das causas primárias, que a metafísica aristotélica legou ao estudo das coisas, é superada pela constatação pragmática de que "cousas ha que hão de ser sempre inaccessiveis aos processos de investigação e verificação de que dispõe o homem” (RIBEIRO, 1880 , p. 11). Em palavras mais decisivas, o que importa não é especular sobre fatos com que as limitações cognitivas do homem não conseguem lidar, mas sim mergulhar em uma análise detalhada e empírica do que pode ser observado e descrito: com esta perspectiva epistemológica, Ribeiro contribui para implantar na linguística brasileira o método experimental.

Para situar a linguística no conjunto das denominadas ciências abstratas, Ribeiro parte de uma classificação dos fenômenos observáveis em seis ordens:

1. de quantidade, extensão e forma, investigados pela Matemática;

2. de movimento, tamanho distância dos astros, investigados pela Astronomia;

3. de calor, luz, eletricidade, magnetismo e acústica, investigados pela Física;

4. de composição e decomposição, investigados pela Química;

5. de organização e vida, investigados pela Biologia;

6. do desenvolvimento das sociedades, investigados pela Sociologia.

Como se percebe, Júlio Ribeiro situa a Sociologia no mesmo plano das ciências físicas e biológicas, de que decorre evidentemente sua crença na possibilidade de um tratamento experimental dos fatos sociais. Reside aqui uma forte influência do denominado evolucionismo social de Edward Tylor e Herbert Spencer, cujas teses aplicam os princípios darwinistas na descrição da sociedade como fruto de um processo evolutivo. A concepção da cadeia etnológica em estágios evolutivos, que vão do primitivo ao civilizado, coadunava-se perfeitamente com os princípios do evolucionismo linguístico que habitavam as páginas de linguistas influentes, tais como August Schleicher e Max Müller.

Este entendimento da Sociologia como ciência intimamente ligada à Antropologia evolucionista dá oportunidade a Júlio Ribeiro para incluir a linguística em seus domínios: "Linguistica é o ramo da sociologia que tem por fim o estudo dos elementos constitutivos da linguagem articulada, e das fórmas diversas que pódem tomar esses elementos" (RIBEIRO, 1880, p. 13). Não se confunda aqui esta concepção sociológica da Linguística com a que Ferdinand de Saussure (18571913) viria mais tarde a utilizar, sob o amparo teórico do fait social de Émile Durkheim (1858-1917), para estabelecer as bases do estudo sincrônico da língua $^{11}$. Aqui, a Linguística vê a língua como objeto histórico, fruto de um processo evolutivo, sem qualquer perspectiva de análise de sua manifestação discursiva no meio social.

Cabe ainda fazer observar uma preocupação de Júlio Ribeiro, nestas linhas iniciais, no tocante à distinção (ainda hoje) pouco definida entre Linguística e

\footnotetext{
11 Ver Durkheim (2001 [1894]). Ao conferir à Sociologia um status ontológico, no sentido de equiparar o fato social às demais coisas que existem concretamente no corpo da sociedade, Durkheim inspira a concepção saussuriana de língua como um organismo imaterial que pode ser estudado como as demais entidades concretas que existem no mundo social. Temos aqui, portanto, uma outra dimensão do relacionamento entre a linguística e a sociologia.
} 
Filologia. A solução de Ribeiro (1880, p. 14), que define a Filologia como estudos dos princípios da linguística aplicados a uma determinada língua "considerada como instrumento e meio de uma literatura", bem se aproxima da distinção que, em geral, se fazia à época entre gramática geral e gramática particular (cf. CAVALIERE, 2000). No entanto, Ribeiro (1880, p. 14) arremata com uma referência especial à Filologia Comparada, que aplica os princípios da Linguística "simultaneamente a varias linguas, cujo parentesco proximo ou remoto se verifica pela comparação". Em síntese, enquanto a linguística cuida dos princípios da linguagem articulada lato sensu, a Filologia Comparada aplica tais princípios em línguas de identidade genealógica, ao passo que a Filologia os utiliza para a análise de dada lingua particular.

\section{Circulando pela Neurolinguística}

As referências superficiais que se costumam traçar acerca da história da Linguística não raro atribuem o nascimento da Neurolinguística, por muitos denominada uma área da Biolinguística (veja o manifesto de Boeckx e Grohmann, 2007), a uma reação, nascida em meados do século XX, à proposta mentalista residente nos estudos de Noam Chomsky sobre a linguagem humana. Esta é a perspectiva que conduz linguistas como Boeckx e Grohmann (2007, p. 1) a afirmar que "os últimos cinquenta anos demonstraram, inequivocamente em nossa opinião, que faz evidente sentido, em vários aspectos, considerar o estudo da faculdade da linguagem como um ramo da biologia, em adequado nível de abstração". Entre os brasileiros, leem-se afirmações como "a neurolingüística constitui-se num campo de investigação relativamente recente, especialmente suscetível aos avanços tecnológicos” (SCHERER; GABRIEL, 2007, p. 68).

Trata-se de afirmações que ordinariamente encontramos nas referências de caráter histórico que esporadicamente se fazem presentes em textos acadêmicos, cuja principal evidência é de que pouco se cuida da veracidade dos fatos históricos quando não há compromisso com a neutralidade epistemológica. A rigor, os primeiros estudos sobre as estruturas cerebrais e seu papel no processamento da linguagem (não obstante a palavra processamento decerto não fosse usada à época) remontam aos estudos de Pierre Paul Broca (1824-1880) e, posteriormente, Karl Wernicke (1848-1905) sobre a afasia. Broca notabilizou-se pela descoberta do locus cerebral responsável pelo processamento da linguagem verbal $^{12}$, ainda hoje conhecido como "área de Broca". A leitura da obra de Broca introduz Júlio Ribeiro na seara dos estudos neulinguísticos que então entravam em voga como resultado da caracterização da novel Glotologia como ciência intimamente vinculada à Antropologia e à História Natural.

No decurso de seus comentários sobre a "sede da linguagem articulada", Ribeiro dá oportunidade para que conheçamos algumas de suas convicções acerca da linguagem humana. Uma delas é a de que a comunicação não é um privilégio do homem, não obstante a faculdade da linguagem articulada o seja: "Mas, si bem que os animaes tenham com certeza ideias, si bem que as saibam communicar, a linguagem articulada está além de seu alcance" (RIBEIRO, 1880, p. 10). Nessa linha, Ribeiro (1880, p. 19-20) estabelece, como distinção essencial entre

12 A descoberta de Broca deveu-se à análise de um paciente afásico que sofria de uma lesão neurossifilítica na circunvolução do lobo frontal esquerda. 
o homem e os demais animais, esta "causa complexa e dificil que a creança tem de aprender na mais tenra edade", arrematando que "é-lhe imposto esse trabalho cerebral em uma épokha muito proxima dos periodos embryonarios, quando o desenvolvimento do hemispherio esquerdo está adiantado em relação ao do hemipherio direito".

Em outros termos, a aquisição da linguagem articulada é um fenômeno congênito, que distingue essencialmente o homem das demais espécies animais. Saliente-se que se está aqui no âmbito da capacidade cerebral de articular a fala, o que se distingue claramente de "competência linguística" em seu sentido chomskyano. Isso se observa sem qualquer dúvida pela afirmação de Ribeiro (1880, p. 21) de que as relações das ideias com as palavras estão no domínio dos dois hemisférios cerebrais:

[...] a faculdade de conceber taes relações pertence as [sic] dous hemisférios que, em caso de molestia, podem supprir-se reciprocamente; mas a faculdade de as exprimir por movimentos coordenados cuja pratica só se adquire em consequência de longo habito, parece pertencer a um só hemispherio que é quasi sempre o esquerdo.

Essa é a explicação que se apresenta à época para o fato de alguns afásicos entenderem a linguagem articulada, não obstante não a possam produzir, além de explicar a existência de afásicos com lesões no hemisfério direito. Essas informações revelam, enfim, que a pesquisa pioneira de Broca e Wernicke limitava-se à investigação do processamento cerebral da língua tão somente quanto à sua "face externa", como à época se denominava, ou seja, quanto ao sistema de sons. Hoje, os estudos neurobiológicos concluíram que a afasia tem etiologia bem mais diversificada, "sugerindo que a linguagem é processada em locais anatomicamente múltiplos e distintos" (BEAR; CONNORS; PARADISO, 2006, p. 639), fato que afasta definitivamente a tese da primazia do lóbulo frontal esquerdo, ou mesmo do próprio hemisfério esquerdo, no processamento da linguagem ${ }^{13}$. Ademais, a neurolinguística contemporânea irmana-se à Linguística Cognitiva na pesquisa do processamento da linguagem no cérebro, não só no tocante à articulação das cadeias sonoras, mas também na construção morfossintática da frase e na estruturação do léxico.

\section{MergulHaNdo NA HistóRIA da LÍNGUA}

As primeiras palavras de Júlio Ribeiro sobre a história da língua são de desesperança. A perspectiva era de que, embora os estudos evolucionistas fossem promissores na seara antropológica, mormente em face da exitosa pesquisa encetada por Ernst Haeckel que nos legou o primeiro modelo de descrição arbórea da genealogia dos seres vivos, a descoberta da origem da linguagem humana era considerada impossivel: "si [a ciência] póde descrever a figura do avô da humanidade, do homo primigenius dolikhocephalo, prognatho [...], si pôde até delimitar o seu habitato; outro tanto não póde fazer relativamente á origem da linguagem articulada" (RIBEIRO, 1880, p. 27). O que temos aqui, com efeito, é uma constatação do princípio positivista de que mais vale dedicar-se à pesquisa em-

13 Sobre o processamento das várias áreas da língua (léxico, sintaxe, fonologia etc.) no cérebro, leia especialmente Kuhl (2004) e Ben Shalom e Poeppel (2008). 
pírica daquilo que está a alcance da ciência do que vagar pela escuridão das ideias especulativas. É sob esse manto epistemológico que Ribeiro (1880, p. 27) assevera: "Historicamente nunca se ha de saber quando e como o grito instinctivo subordinou-se a regras para converter-se em palavra, quando e como o anthropoide se fez homem".

Há, sim, a crença de que a linguagem articulada é fruto do ajustamento do aparelho fonador à necessidade de emitir sons variados, o que por sua vez decorre da pluralidade de itens lexicais que se iam produzindo pela faculdade da designação das coisas. As indagações giram em torno da origem monofilética ou polifilética da linguagem, cuja investigação, naturalmente, recorre a estratégias de analogia com a expressão vocal em outros animais, tais como a variação tonal no latido dos cães e no guincho dos macacos. Aqui, a explicação para que o homem tenha desenvolvido privativamente a faculdade da linguagem articulada reside no exclusivismo de uma senda evolutiva:

Com o correr do tempo as concepções homologaram-se com os seus instrumentos, as idéias hyposthatisaram-se com as palavras, e o pensamento e a linguagem articulada começaram a marchar par a par, auxiliando-se mutuamente sem mais se poderem separar (RIBEIRO, 1880, p. 33).

Essa concepção evolucionista sobre a origem da lingua, que implica, naturalmente, uma investigação mais dedicada à fisiologia do homem do que propriamente à linguagem como meio de expressão, faz edificar uma sequência de períodos pré-históricos e históricos, frutos da especulação sobre o despertar no homem da faculdade da fala.

\section{A EVOLUÇÃO DA LÍNGUA: NASCER, VIVER, MORRER}

O capítulo 4 dos Traços introduz o leitor nessa excitante teoria evolucionista da língua, sob clara inspiração das teses publicadas por August Schleicher e Max Müller na área da linguística histórico-comparativa ${ }^{14}$. Surpreendentemente, o argumento de autoridade que Ribeiro utiliza em seu texto repousa não nos linguistas mencionados, senão em Charles Darwin, especificamente no tocante à sua teoria da evolução aos principios da seleção natural. A opção por Darwin, em detrimento das fontes diretas na seara da Linguística, talvez se justifique pelo exponencial conceito que o naturalista britânico já desfrutava à época no mundo científico, com expressiva amplitude após a publicação de seu On the Origin of Species em novembro de 1959, e que se consolidou ao longo do tempo. Essa rara projeção de um cientista entre seus contemporâneos fez de Darwin "um colosso que pairava acima de todos os outros cientistas oitocentistas", como bem expressa Keith Francis (2007 [1859]) no prefácio da excelente edição preparada pela Greenwood Press ${ }^{15}$.

O raciocínio analógico que interpreta o fenômeno linguístico à semelhança dos seres vivos e das leis que regulam a seleção das espécies percorre todo o

\footnotetext{
14 Embora não o cite textualmente, Ribeiro decerto teve acesso ao texto Nouvelle leçons sur la Science du langage (1863), uma tradução para o francês das palestras que Max Müller proferira na Universidade de Oxford em 1861 e 1863. Júlio Ribeiro (1911 [1881], p. 6), entretanto, cita essa obra de Müller na Gramática portuguesa ao tratar do caráter vocal tanto das vogais quanto das consoantes.

15 Sobre a controvérsia criada acerca da mitificação de Darwin como gênio da ciência oitocentista, leia especialmente Browne (2005).
} 
capítulo. Fica, então, o leitor instruído de que a língua é um ser que decerto desaparecerá, como desaparecem os seres em geral, devido ao processo de seleção natural: "Bem como as especies organicas que povoam o mundo, as linguas, verdadeiros organismos sociologicos, estão sujeitas á grande luta pela vida, á lei da selecção" (RIBEIRO, 1880, p. 42). Vê-se, pois, que o uso do termo "evolução da língua", que mais tarde seria substituído nos paradigmas do século XX por "câmbio linguístico" (no Brasil, em especial, "mudança linguística") não ia além de um empréstimo terminológico de que se serviu a Linguística dos Oitocentos.

Segundo Ribeiro, o fato de que as línguas modernas estão sujeitas a expressiva variação dialetal justifica-se pela grande fragmentação social dos povos, pela ausência de um governo centralizador que zele pela unidade linguística, um indício significativo da relação que o linguista mineiro estabelecia entre língua e Estado. No entanto, em mais uma expressiva analogia no campo da História Natural, Ribeiro justifica o surgimento de dialetos em dada lingua em face de causas externas naturais, como o clima, e culturais, como os costumes sociais. No âmbito das causas culturais, a rigor, as ideias trazidas por Ribeiro não diferem radicalmente das que a teoria da mudança linguística proporia no século seguinte: causas como o contato linguístico e a criação lexical decorrente da nova ordem social são referidas, mas sempre numa perspectiva evolucionista, em que há os que sucumbem em face da concorrência de outros mais qualificados. Também são válidas até hoje algumas constatações, como a de que a sobrevivência de uma língua depende da existência do falante. A questão está em que, hoje, esse é um fator, entre outros de caráter politico, que pode conduzir ao desaparecimento de uma língua, como bem atestam os estudos sobre linguas minoritárias.

A perspectiva naturalista com que Ribeiro interpretava o fenômeno da linguagem decerto lhe impedia ver nas linguas modernas um estado contemporâneo de línguas anteriores, muito menos admitir que a rigor tenhamos hoje versões atualizadas de linguas antigas. Se a civilização romana desapareceu, como conceber que a língua que falavam os romanos sobreviva hoje nas línguas românicas? Parece haver aqui certa submissão do fato ao princípio, no sentido de que o cientista tem a visão dos fatos enevoada pelo compromisso imposto pelo paradigma. Com efeito, foram os comparativistas do século XIX que vincularam fonológica e morfologicamente as línguas modernas às "linguas mortas", mas a força do paradigma impedia que notassem a (atual) obviedade de que as identidades morfológicas expressas por raizes, temas, prefixos etc. fossem as evidências de que as línguas não morrem, porém mudam.

Esta hipótese se consolida ao lermos, no fluxo das analogias que Ribeiro (1880, p. 47) oferece ao leitor, o seguinte passo:

As especies extinctas não reaparecem mais: a marcha do tempo e as variações acumuladas tornam impossivel a volta de condições identicas de vida. Do mesmo modo nenhuma lingua morta poderá reviver, porque a mudança de costumes, os progressos das sciencias e das artes, as necessidades novas cavam entre o passado e o presente um abysmo cada vez mais insondável.

A título de ilustração, reproduzimos, a seguir, o quadro analógico de Júlio Ribeiro (1880) acerca da evolução dos seres vivos e das línguas: 
Quadro 1 - A selecção

\begin{tabular}{|l|l|}
\hline nas especies & nas linguas \\
\hline $\begin{array}{l}\text { As especies têm suas variedades, obra do } \\
\text { meio ou de causas physiologicas. }\end{array}$ & $\begin{array}{l}\text { As linguas têm seus dialectos, obra do } \\
\text { meio ou dos costumes }\end{array}$ \\
\hline $\begin{array}{l}\text { As espécies vivas descendem geralmente } \\
\text { das especies mortas do mesmo paiz }\end{array}$ & $\begin{array}{l}\text { As linguas vivas descendem geralmente } \\
\text { das línguas mortas do mesmo paiz. }\end{array}$ \\
\hline $\begin{array}{l}\text { Uma especie em um paiz isolado passa por } \\
\text { menos variações. }\end{array}$ & $\begin{array}{l}\text { Uma lingua em um paiz isolado passa por } \\
\text { menos variações. }\end{array}$ \\
\hline $\begin{array}{l}\text { Variações produzidas pelo cruzamento } \\
\text { com especies distinctas ou extrangeiras }\end{array}$ & $\begin{array}{l}\text { Variações produzidas pela introdução de } \\
\text { palavras novas, devidas ás relações exte- } \\
\text { riores, ás sciencias, á industria. }\end{array}$ \\
\hline $\begin{array}{l}\text { A superioridade das qualidades physicas, } \\
\text { assegurando a victoria aos individuos de } \\
\text { uma espécie, causa de seleção. }\end{array}$ & $\begin{array}{l}\text { O genio e a instrucção publica centralisa- } \\
\text { da, causas de seleção. }\end{array}$ \\
\hline $\begin{array}{l}\text { A beleza da plumagem ou a melodia do } \\
\text { canto, causa de seleção. }\end{array}$ & A brevidade ou a eufonia, causas de seleção. \\
\hline Lacunas numerosas nas especies extinctas. & Lacunas numerosas nas linguas extinctas. \\
\hline $\begin{array}{l}\text { Probabilidade de duração de uma especie } \\
\text { no numero de individuos que a compõem. }\end{array}$ & $\begin{array}{l}\text { Probabilidade de duração de uma lingua } \\
\text { no numero de individuos que a fallam. }\end{array}$ \\
\hline As especies extinctas não reaparecem mais. & As linguas extinctas não reaparecem mais. \\
\hline $\begin{array}{l}\text { Progresso nas especies pela divisão do tra- } \\
\text { balho physiologico. }\end{array}$ & $\begin{array}{l}\text { Progresso nas linguas pela divisão do tra- } \\
\text { balho intellectual. }\end{array}$ \\
\hline
\end{tabular}

Fonte: Ribeiro (1880, p. 59-60).

\section{Conclusão}

Estas linhas, evidentemente, sequer tangenciam as inúmeras vertentes de investigação historiográfica que nos proporciona este precioso Traços gerais de linguística, uma obra que merece melhor e mais cuidadosa análise por parte dos historiógrafos da linguística no Brasil. As ideias expostas por Júlio Ribeiro sobre a constituição do aparelho fonador e sua função de articular o som da língua, por exemplo, estendem-se por uma descrição anatômica do trato vocal que bem expressa a vinculação íntima entre a análise linguística e a análise anatômica que caracteriza o último quartel dos Oitocentos. Também estão no opúsculo de que vimos tratando os princípios da seleção natural aplicáveis às espécies animais, agora a serviço da descrição da língua, de que decorre uma exposição diacrônica das fases linguísticas da humanidade que deram vezo a línguas monossilábicas, aglutinantes, flexionais e contratas, nessa sequência de aperfeiçoamento de um organismo, no decurso do tempo, para melhor servir ao propósito de expressar as ideias.

São conceitos que se avolumam a cada página lida, dado o perfil intensamente informativo do opúsculo, fato que, por sinal, não raro o afasta do escopo maior de trazer a ciência linguística ao conhecimento do cidadão comum. Evidencia-se, pois, a necessidade de que estudos renovados se voltem para esse produto da Linguística brasileira no século XIX, de tal sorte que 
possamos melhor entender o percurso da produção e difusão do pensamento linguístico no Brasil.

\section{THE FIRST STEPS OF THEORETICAL LINGUISTICS IN BRAZIL}

Abstract: This paper intends to coment on the text Traços gerais de linguística, by Júlio Ribeiro, that has been published in 1880 as one of several other similar works dedicated to the project of science vulgarization in the Brazilian scenario of the 19th century. This small book, in historiographical perspective, can be understood as the first Brazilian study on theoretical linguistics, whose pages expose the main evolucionary linguistic concepts that characterize the 19th century attempt to explain the origin of human speech, as well as the mechanisms of language processingin the brain.

Keywords: Linguistic historiography. Forerunner text. Brazilian linguistics.

\section{REFERÊNCIAS}

BEAR, M. F.; CONNORS, B. W.; PARADISO, M. A. Neurociências: desvendando o sistema nervoso. 2. ed. Porto Alegre: Artmed, 2006.

BÉGUET, B. La science pour tous: sur la vulgarisation scientifique en France de 1850 à 1914. Paris: Conservatoire National des Arts et Metiers, 1990.

BEN SHALOM, D.; POEPPEL, D. Functional anatomic models of language: assembling the pieces. Neuroscientist, n. 14, p. 119-127, 2008. Disponivel em: <http://www.researchgate.net/publication/5934283_Functional_Anatomic_ Models_of_Language_Assembling_the_Pieces>. Acesso em: 24 jan. 2017.

BOECKX, C.; GROHMANN, K. K. The Biolinguistics manifesto. Biolinguistics, n. 1, p. 1-8, 2007. Disponivel em: <http:/ /www.biolinguistics.eu>. Acesso em: 24 jan. 2017.

BROWNE, J. Presidential address commemorating Darwin. The British Journal for the History of Science, v. 38, p. 251-274, Sept. 2005.

CAVALIERE, R. Fonologia e morfologia na gramática científica brasileira. Niterói: Eduff, 2000.

COBRA, E. C. de O. Júlio Ribeiro: educação e religião no Brasil oitocentista. 2011. Tese (Doutorado em Educação)-Universidade Metodista de Piracicaba, Piracicaba, 2011. Mimeo.

COSTA E CUNHA, A. E. da. Grammatica elementar portugueza, adaptada ao ensino das escolas de instrucção primaria, quer dos menores, quer dos adultos, e bem assim dos Collegios, Liceos e Escolas Normaes e aulas preparatorias. Rio de Janeiro: [s. n.], 1880.

COSTA, J. C. Contribuição à história das idéias no Brasil. Rio de Janeiro: Livraria José Olimpio, 1956.

DUCOS, J. Présentation. In: DUCOS, J. (Ed.). Encyclopédie médiévale et langues européennes: réception et diffusion du De proprietatibus rerum de Barthélemy l'Anglais dans les langues vernaculaires. Paris: Editions Honoré Champion, 2014. 
DURKHEIM, É. Les règles de la méthode sociologique. Édition électronique réalisée avec le traitement de textes Microsoft Word pour Macintosh. 2001 [1894]. Disponivel em: <http://classiques.uqac.ca/classiques/Durkheim_emile/regles_methode/durkheim_regles_methode.pdf>. Acesso em: 24 jan. 2017.

FRANCIS, K. A. Charles Darwin and the origin of species. Westport: Greenwood Press, 2007 [1859].

HOUAISS, A. Elementos de bibliologia. Rio de Janeiro: Instituto Nacional do Livro/Ministério da Educação e Cultura, 1967. v. II.

ILARI, R. Linguística e ensino da língua portuguesa como lingua materna. São Paulo: Museu da Língua Portuguesa, 2009. Disponivel em: <http:/ /www.museudalinguaportuguesa.org.br/files/mlp/texto_3.pdf>. Acesso em: 24 jan. 2017.

IRMÃO, J. A. Júlio Ribeiro. Sorocaba: Editora Cupolo, 1978.

KUHL, P. Early language acquisition: cracking the speech code. Nature Reviews, v. 5, p. 831-843, 2004. Disponivel em: <http://www.nature.com/nrn/journal/ v5/n11/full/nrn1533.html>. Acesso em: 24 jan. 2017.

KUHN, T. The essential tension: selected studies inscientific tradition and change. Chicago: The University of Chicago Press, 1977.

LEITE, Y. Joaquim Mattoso Câmara Jr: um inovador. Delta: Documentação de Estudos em Linguística Teórica e Aplicada, v. 20, p. 9, 2004.

LINS, I. História do positivismo no Brasil. 2. ed. São Paulo: Companhia Editora Nacional, 1967.

MARQUES, A. A. S. Interesses da Colonia Portugueza na Provincia de S. Paulo, Brazil: artigos publicados na "Provincia de São Paulo". Primary Source ed. Nabu Press, 2013.

MASON, C. P. English grammar. 27. ed. Toronto: Adam Miller, 1879 [1858].

MATOS, F. G. de. O Dicionário de Lingüística e Gramática: notas de um leitor-posfaciador. Delta: Documentação de Estudos em Linguística Teórica e Aplicada, v. 20, p. 159, 2004.

MÜLLER, M. Nouvelle leçons sur la science du langage. Paris: A. Durant et Pedone Lauriel Libraires-Éditeurs, 1863. Off. de Simao Thaddeo Ferreira, 1806.

OLIVEIRA, A. P. C. de; MATTA, A. B. S. da. A constituição da "Philologia" em "O vulgarisador": uma análise discursiva. Cadernos do CiFEFiL, Rio de Janeiro, v. XV, n. 5, t. 2, p. 1105, 2011.

RAICHVARG, D.; JACQUES, J. Savants et ignorants; une histoire de la vulgarisation des sciences. Paris: Éditions du Seuil, 1991.

RIBEIRO, J. Traços geraes de linguistica. São Paulo: Livraria Popular de Abilio A. S. Marques, 1880.

RIBEIRO, J. A Carne. Rio de Janeiro: Livraria Teixeira, 1888.

RIBEIRO, J. Cartas sertanejas. 2. ed. Lisboa: Livraria Clássica Editora de A. M Teixeira, 1908.

RIBEIRO, J. Grammatica portugueza. 10. ed. Rio de Janeiro: Livraria Francisco Alves, 1911 [1881].

RODRIGUES, A. D.'I. A obra científica de Mattoso Câmara Jr. Estudos da Lingua(gem), Vitória da Conquista, n. 2, p. 11-28, dez. 2005. 
SCHERER, L. C.; GABRIEL, R. Processamento da linguagem: contribuições da neurolinguística. Signo, v. 32, n. 53, p. 66-81, dez. 2007.

SILVA, A. de M. Epitome da grammatica da lingua portugueza. Lisboa: Off. de Simao Thaddeo Ferreira, 1806.

SILVA, I. B. da. Júlio Ribeiro: leitura sobre a trajetória de um intelectual maçom e protestante na cidade de Sorocaba na segunda metade do século XIX. Revista Confluências Culturais, v. 1, n. 1, p. 29, set. 2012.

SILVEIRA, C. R. da. Intervenções e polêmicas: Júlio Ribeiro no universo letrado paulista. In: ENCONTRO REGIONAL DE HISTÓRIA: PODER, VIOLÊNCIA E EXCLUSÃO, 19., 2008, São Paulo. Anais... São Paulo, USP, 2008. Disponível em: <http://www.anpuhsp.org.br/sp/downloads/CD\%20XIX/PDF/Autores\%20 e\%20Artigos/Celia\%20Regina\%20da\%20Silveira.pdf>. Acesso em: 24 jan. 2017. SOARES, M. P. O positivismo no Brasil: 200 anos de Augusto Comte. Porto Alegre: AGE, Editora da Universidade, 1998.

TORRES, J. C. de O. O positivismo no Brasil. 2. ed. Petrópolis: Vozes, 1957.

UCHÔA, C. E. F. Mattoso Câmara: um novo discurso sobre o estudo da linguagem no Brasil. Delta: Documentação de Estudos em Linguística Teórica e Aplicada, v. 20, p. 1, 2004.

VANDRESEN, P. Mattoso Câmara 100 anos: uma homenagem do Círculo de Estudos Linguísticos do Sul. In: ENCONTRO CELSUL, 6., 2006, Florianópolis. Anais... Florianópolis: UFSC, 2006. Disponivel em: <http://www.celsul.org.br/ Encontros/06/Palestras/01.pdf>. Acesso em: 24 jan. 2017.

Recebido em novembro de 2016. Aprovado em novembro de 2016. 